Available online at: http:// http://tsdr.psdku.unpad.ac.id

Tourism and Sustainable Development Review Journal (TSDR)

ISSN 2722-2152 (online)

Volume 2 Number 1 (2021): 49-64

\title{
A Study on Sustainable Event Management Practices in Sri Lanka; Event Managers' Perspective
}

\author{
A.M.D.B. Nawarathna ${ }^{1}$, R.S.S.W. Arachchi ${ }^{2}$ \\ ${ }^{1}$ Department of Tourism Studies, Faculty of Management, Uva Wellassa University, Sri Lanka \\ ${ }^{2}$ Department of Tourism Management, Faculty of Management Studies, Sabaragamuwa University, \\ Sri Lanka
}

\begin{abstract}
Sustainability practices have begun to take hold in all kinds of events, and there are very few forces or mechanisms driving the widespread adoption and expansion of sustainable event management to become a common practice throughout the community in Sri Lanka. Hence, the central focus of the study was to identify the current sustainable event management practices in Sri Lanka. Primary data collected through structured interviews from 15 event managers who have membership of the Sri Lanka Association of Professional Conference, Exhibition, and Event Organizers by using the purposive sampling technique. A qualitative data analytical method was employed, and the collected data were transcribed and analyzed by using content analysis. The findings of the study reveal that targeting high-end events, better planning, strengthening the local communities, cultural conservation, waste management, energy efficiency, and dissemination of information are the current sustainable event management practices in Sri Lanka. Further, the findings elucidate effective theoretical and managerial implications for event organizers, government, and residential communities where events are held. Moreover, maximize the awareness of sustainable education, develop a sustainable event model, adapt to the green-related technology, introduce green venues and promote sustainable events, government involvement of making policy framework and privatepublic partnership create long term and sustainable legacies for host communities and development of sustainable event management in Sri Lanka.
\end{abstract}

Keywords: Sustainable event management, Economic sustainability practices, Social sustainability practices, Environmental sustainability practices

This is an open access article under the CC-BY-NC license.

\section{INTRODUCTION}

The event sector of the tourism industry is young, dynamic, growing, and maturing at a rapid rate. From its origins in North America and Europe, it is now a truly global sector of the tourism industry. Particularly, events become an important component of the tourism industry, which most of the events are hosted in an economically, socially, and environmentally responsible way. Significantly, the event industry might cause economic growth and infrastructure development in many countries.

Events witness a range of impacts on both positive and negative aspects on their host communities and stakeholders. Global warming has paved the attention of most event organizers to rethink and posture their attitude on the environment and resource preservation in the event industry. Moreover, in the current world of work, environmental sustainability has become progressively significant, and organizations influence to involve and development of sustainable

Corresponding Author

A.M.D.B. Nawarathna, dhananjaya@uwu.ac.lk, dhana1991bandara@gmail.com; R.S.S.W. Arachchi,

rangana@mgt.sab.ac.lk 
policies and practices in harvesting the best products that attract the trending markets of been environmentally friendly products. The aspects are common and viable in the tourism and event industry that lead to the durable industry in the future.

Therefore, sustainable management practices to be enhanced with more advanced techniques in the field of event management in the world. "Various international festivals and events and many international companies are making event greening a part of their tender process" (Ahmad et al., 2013). In creating an event surrounding and appearance in the proper paths of sustainability, all the procedures of the event, from top to bottom, have to be remerged with sustainable policy developments in the field. "A sustainably managed event is one in which sustainability awareness, design, and decision-making are fully integrated into its management logistics, operations, and production. It has been evolving over the past two decades and is rapidly growing in recognition, both in the national and international event industries while also, event coordinators increasingly seek to improve the sustainability credentials of events" (Laing \& Frost, 2010).

Sustainability in event management integrates both socially and environmentally friendly decision-making into event planning, organizing, and implementation processes. The British Standards Institution (2012) defined sustainable event management as "an enduring balanced approach to economic activity, environmental responsibility and social progress". And also, Dwyer et al. (2005) defined the same aspect as "the manner in which events are organized taking into consideration the social, environmental and economic impacts".

"Sustainability practices have begun to take hold in all kinds of events including conferences and meetings, trade shows and expositions, mega events, sporting events, festivals, religious or cultural celebrations, and community and civic events" (Sustainable Event Alliance, 2011). Although sustainable event management endures cultivating its popularity in the markets, still it has not become a common scenario or practice in the community since the forces or mechanisms that drive the extensive implementations and expansions of sustainable event management have not impressively exhibited in the society and are hidden practices that community does not recognize at a glance. Hence, an essential requirement arises in defining the clear strategic approaches to launch in event management practices. "A need exists to identify strategies that will help event organizers engage and improve sustainable event management of tourism industry" (Stettler, 2011).

Maguire and Hanrahan (2013) stated festivals and events generate the vast majority of negative impacts in different areas, and the urgency of sustainability is clear, and society should acknowledge this. Further, they mentioned there is an apparent need for festivals and events to be sustainably managed and therefore utilize and adopt new sustainability technologies in order to minimize costs and plan and manage for cleaner and more sustainable festivals and events. Moreover, it is a necessity to identify appropriate strategies to maximize the benefits of events for the interest of different communities in the scale of sustainability (Schulenkorf et al., 2018).

Chiu et al. (2020) also cited; "event organizers should try to plan, organize, manage and stage a greener sport event in order to reduce the negative impacts and optimize the opportunities. Essentially, the sustainability of the events requires responsible actions, social and environmental protection, to meet the current needs of consumers and businesses and agreeing to maintain or increase the resources for future generations to meet their needs". 
According to the literature, many scholars working on economic impact studies aimed at assessing the economic value of events and festivals with quantifiable monetary estimates of worth and their economic impact on the host region (Getz, 2009; Smith, 2009; Stettler, 2011). Even though these economic impact studies are conducted to assess the potential benefits and costs of economic development, there is a gap in the literature concerning a sustainable development perspective. According to Smith (2009), major events are often justified by host communities for their contribution to economic development but often end up creating a development that is unsustainable because of the durable impacts they consent to compromise the ability of host communities in fulfilling their own needs. Further, mega-events have also come under great criticism for launching city development that is neither socially nor economically sustainable and doesn't consider the long-term benefits of the host community. Getz (2009) also noted that the events' literature is missing sustainability components.

Further, hosting an event requires great amounts of resources, including water, energy, material purchasing, transportation, and various other resources that result in waste and greenhouse gas emissions. "Stakeholders involved in the festival or event may not be sure how to or where to start in reducing the impacts that arise from not managing these resources in an efficient and effective manner" (Maguire \& Hanrahan, 2013).

Moreover, Sri Lanka has been identified a number of opportunities that can be created through effective promotion of business tourism and MICE tourism, and the sustainability of the tourism industry is strongly linked with environmental and socio-cultural aspects of a destination (Wickramasinghe, 2018). Additionally, the existing fragmentation of the planning, management, and policymaking related to tourism event creation and the associated and overlapping legal, regulatory and institutional responsibilities are key challenges to address sustainable tourism development in the Sri Lankan context. And also, to the best of the author's knowledge, there is no research on this topic in the Sri Lankan context. Therefore, this research seeks to fulfill some of these gaps that have been identified and develop effective, sustainable event management practices and contribute to the Sri Lankan tourism industry.

\section{LITERATURE REVIEW}

\section{Sustainable Event Management}

Sustainable event management has evolved over many years and is not a term that emerged from policy, policies, or academic posturing. A natural advance is a recent proposal to convert past and present systems to a known standard. A conceptual framework that has evolved over the last ten years from event planning and management is a basic requirement for a responsible professional event throughout the $21^{\text {st }}$ century.

Sustainability and event management are relative concepts when combined to make sustainable event management (Jones \& Scanlon, 2010), but if we want to achieve the best results, both need to be managed responsibly. Currently, sustainability and event management are gaining increasing popularity among academics and professionals (Getz, 2009; Holmes et al., 2015; Jones \& Scanlon, 2010). Events may vary in their impact but may also affect economic, tourist/business, biophysical, social, political, social, and environmental factors (Holmes et al., 2015). Therefore, sustainability in event tourism requires a process that captures positive host 
community involvement to enable and maintain the event experience and the destination's attractiveness.

The concept of sustainability has three components as environmental, economic, and social, which are classified as the Triple Bottom Line (TBL). The word sustainability has become an important topic in today's community, especially within the tourism industry (Byrd, 2007) and now the event industry as well. Thus, sustainable practices include the removal of harmful substances that are produced by the environment and gaining benefits to the community and economy. Events produce impacts across the triple bottom line (TBL), which refers to the economy, socio-culture, and the environment. The result can be positive and negative, tangible in addition to intangible. While tangible impacts relate to material outcomes, intangible impacts entail non-material effects such as socio-cultural benefits and costs as well as socio-economic benefits and costs (Dwyer, L., Mellor, R., Mistilis, N., \& Mules, 2000).

And also, sustainable event management is a collection of tools, processes, and procedures that event organizers and operators use to make events greener. The British Standards Institution (2012) described the sustainable event as a means to cope with economic activity, climate responsibility, and social progress. According to Tzila (2007), sustainable event management is the convergence of sustainability with the project planning process of event management. The combination of sustainability and events management creates a better future for the community, the economy, and the rest of the environment. Event organizers increasingly seek to improve sustainability, and a sustainable event is a popular event with the media and the public (Laing \& Frost, 2010).

For events to contribute to sustainable development, there must be a balance between economic, social, and environmental objectives with strategies in place for optimizing positive and minimizing negative impacts. Therefore, it is important to recognize the unique features of events and the events industry and develop operational strategies whereby event stakeholders act responsibly and thereby contribute to development.

\section{Economic Sustainability Practices}

Economic sustainability implies the efficient and effective use of accessible means and ensures that all money-related commitments can be met in a timely manner. Economic and social considerations must also be taken into account with the likelihood of a possible recovery. A central theme of recent event reconstruction literature is that cities will strive to draw on established economic capital. It is necessary to ensure that small businesses and vulnerable people can benefit from futures contracts that are usually associated with large events. Support for local businesses may be needed, especially as there are indications that events could harm them. Although the Barcelona Olympics are widely celebrated, they have expelled hundreds of small businesses from places that have historically offered low rents (Higham, 2005). The organizers of the London Olympics also had to discuss the relocation of 284 companies in preparation for the 2012 Games (Holmes et al., 2015).

As well as identifying the regeneration of events in general, it is necessary to develop criteria for evaluating its sustainability. O'Sullivan and Jackson (2002) assessed events based on eight criteria for sustainable economic development as empowerment and access to public education and training, community service, community development, sustainable business 
processes, business responsibility, availability and distribution of services, and business in the region. These guidelines are skewed towards concentrating on economic problems, but they also show that general principles can be used to evaluate event sustainability.

Sustainable events support the flourishing of economic practices through collaboration and partnerships, local support, equal economic impact, transparency, and accountable governance (Endorser, 2019). Holmes et al. (2015) suggest that companies will work together to become economically viable and that past industrial methods of management and economics would take decades to move. Furthermore, to ensure economic sustainability, it is important that event planners use long-term perspectives in sustainable event management.

\section{Social Sustainability Practices}

Social sustainability practices require a balance between social and economic equality. This means respecting community rights and distributing equal rights to all members of the community to reduce poverty. People need to think about their needs and preferences, increase the standard of living in the city, manage and value their lives, and identify and value its different cultures (Hall et al., 2010). Social factors include basic human rights, effect on the environment, working practices, cultural respect, protection, and health and wellbeing (Endorser, 2019).

Social sustainability is accomplished by meeting the needs of everyone involved in organizing or triggering an event equally. Pfeffer (2011) argues that organizations that are socially sustainable will ensure the beneficial effect of management practices on employee wellbeing. In addition to external impacts on host communities, local cities, and indirectly impacted populations, the company will consider the internal impact on workers and direct stakeholders. The provision of health care, health and education, low-paid leave, good working hours, living wages, equal employment, and regular work can all be in normal social skills. External social sustainability activities will greatly contribute to the social sustainability of the host city of the organization, especially in the areas of governance, social and cultural life, social development and public services, urban real estate, transport and convenience, economic reform, and public infrastructure development(Caulfield et al., 2001).

\section{Environmental Sustainability Practices}

Environmental sustainability involves making decisions and using exercises to minimize planetary degradation. Environmental considerations mainly apply to products that are used and designed, presented, and picked up by the organizers, guests, and other parties participating in the event. Some of these factors can directly affect the event planner, but other factors are more responsible to suppliers. It is important to remember that organizing a "green" event does not necessarily make it more expensive right away.

The sustainability of the environment lies in making decisions and engaging in practices that minimize the degradation of the earth. Sustainability factors mainly refer to products and are used by the organizer, guests, and other stakeholders while planning, implementing, and participating in events. An important comment to make here is that organizing a "green" event does not necessarily mean that it will automatically become more expensive. In fact, many environmental plans can reduce costs and increase efficiency if done correctly. It refers specifically to major events such as conferences and sports. 
According to the United Nations Environment Program (2009), "A green event is planned, coordinated, implemented in a way that reduces the negative impact on the environment and leaves a positive legacy for the host community". There are a variety of green practices, including waste reduction strategies, recycling initiatives, and water protection, but there are also more and more creative steps through which events can lead to greener activities (Laing \& Frost, 2010).

Green practices can include waste minimization and recycling, energy management, pollution reduction, zero emissions, water savings, material use reduction, material life cycle assessment, and toxicity reduction (Braungart et al., 2007). Basic environmental activities include resource recycling, waste management, carbon capture and control, supply chain management, responsible sourcing, and biodiversity protection.

\section{Concept Indicator Model}

The researcher has developed a concept indicator model based on the indirect empirical representations to define the research concept. According to the research, the researcher has developed four indicators as definition, antecedents, sustainable event management practices, and challenges to validate and interpret their results.

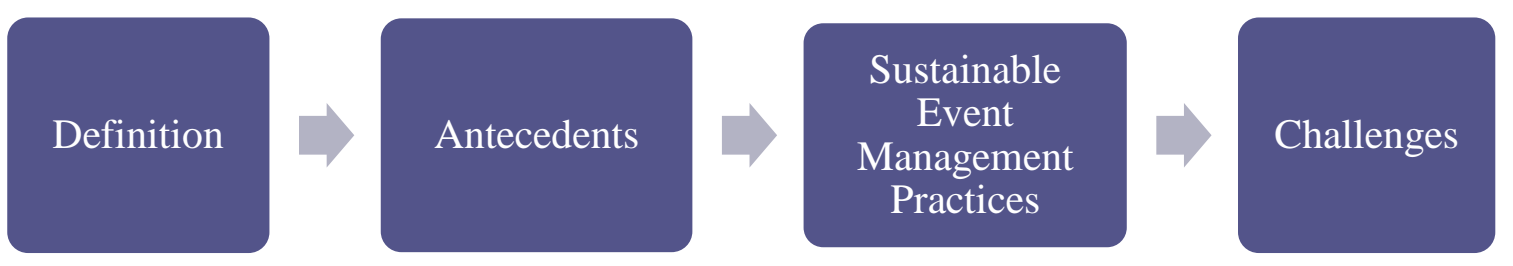

Figure 1: Concept Indicator Model

Source: Developed by the Researcher (2020)

\section{RESEARCH METHOD}

This study is mainly based on the primary data which has been collected via structured interviews selected from the events companies, which are members of the Sri Lanka Association of Professional Conference, Exhibition and Event Organizers (SLAPCEO) in Colombo, Sri Lanka (2020). The purposeful sampling technique used for this research and 15 events companies were interviewed who were the members of SLAPCEO in Sri Lanka for this study as the sample size.

An interview guide was created after the research objectives, and goals were established. Usually, this guide consists of 11 main questions, and several sub-questions are included wherever necessary for this study. The interview guide itself was developed, including general questions about the company background and questions about the sustainable event management practices in Sri Lanka. The aim of general questions was to get background information about the company and about the motivations for organizing a sustainable event. Questions were raised about how many years in the industry, the number of events per year, and the type of event.

The main objective of the research was to identify sustainable event management practices in Sri Lanka. Therefore, the researcher has developed sub-questions as economic sustainability 
practices, social sustainability practices, and environmental sustainability practices in order to achieve the objective. Further, the last question aimed to determine the respondents' opinion about promoting the sustainable event in a better and more efficient way to increase the number of sustainable events in a Sri Lankan context.

Interview participants were contacted via phone, e-mail, in-person, or a combination of the previous. All fifteen interviews were held via phone and person. The length of each interview ranged from 45 minutes to 60 minutes. After the interview, each conversation was transcribed and reviewed again by the researcher. Every transcript was sent to the respective respondent to get confirmation that the information recorded is correct. The revised transcripts were then analyzed.

According to the research, the researcher has used content analysis as the data analysis method, and it is the most widely used method of qualitative data analysis that focuses on the identification of patterned significance across a dataset. It aims to identify meaning patterns across a dataset that provide an answer to the research question to be dealt with. Patterns are defined by a comprehensive data familiarization process, data coding, and categories creation and revision.

In this study, the researcher coded the data into key three codes in order to achieve the research objective and subdividing relevant data into subsections under those codes. It is illustrated in Table 1.

Table 1: Codes Summary

\begin{tabular}{|c|c|c|c|}
\hline Data & Code & Categories & Sub Categories \\
\hline \multirow[t]{14}{*}{ Objective 01} & \multirow{5}{*}{$\begin{array}{l}\text { Economic } \\
\text { sustainability } \\
\text { practices }\end{array}$} & \multirow{2}{*}{$\begin{array}{l}\text { Targeting high-end } \\
\text { events }\end{array}$} & Branding \\
\hline & & & Networking \\
\hline & & \multirow[t]{3}{*}{ Better planning } & Cost reduction strategies \\
\hline & & & Standardization \\
\hline & & & Income-generating strategies \\
\hline & \multirow{7}{*}{$\begin{array}{l}\text { Social } \\
\text { sustainability } \\
\text { practices }\end{array}$} & \multirow{4}{*}{$\begin{array}{l}\text { Strengthening the } \\
\text { local communities }\end{array}$} & Educate society \\
\hline & & & \\
\hline & & & Community empowerment \\
\hline & & & Corporate Social Responsibility \\
\hline & & \multirow[t]{3}{*}{ Cultural conservation } & Promote traditional events \\
\hline & & & Comply with local culture \\
\hline & & & Comply with law \\
\hline & \multirow{2}{*}{$\begin{array}{l}\text { Environment } \\
\text { sustainability }\end{array}$} & \multirow[t]{2}{*}{ Waste management } & Usage of waste bins \\
\hline & & & Avoid plastics and polythene \\
\hline
\end{tabular}


Tourism and Sustainable Development Review Journal (TSDR), Vol. 2 (1), 49-64

A Study on Sustainable Event Management Practices in Sri Lanka; Event Managers' Perspective A.M.D.B. Nawarathna, R.S.S.W. Arachchi

\begin{tabular}{|l|l|l|l|}
\hline \multirow{5}{*}{} & practices & Usage of technological equipment \\
\cline { 3 - 3 } & & Online registration \\
\cline { 3 - 4 } & Energy efficiency & Usage of natural air \\
\cline { 3 - 4 } & $\begin{array}{l}\text { Dissemination of } \\
\text { information }\end{array}$ & Usage of LED equipment \\
\cline { 3 - 4 } & & Environmental standards \\
\hline
\end{tabular}

Source: Developed by the researcher (2020)

\section{FINDINGS AND DISCUSSION \\ Findings}

The main objective of the research was to identify sustainable event management practices in Sri Lanka. Analyzing the interview responses given by the respondents, the researcher has identified the main three sustainable practices in Sri Lankan events industry as economic sustainability practices, social sustainability practices, and environmental sustainability practices. According to the research, the researcher has been identified five key economic sustainability practices, and these practices based essentially on targeting high-end events and better planning in events. The first category of the economic sustainability practice was targeting high-end events, which became one of the most important practices around the Sri Lankan event companies. Any business organization aims to earn more profits in the short run and long run stages. The events industry is considered the fastest growing industry in the Asian context. In a scenario like that identifying the right market and identifying the demand are very much important to get the maximum benefit of the resources.

Sri Lankan events industry can expand into different sectors, and it can attract more potential customers and create a competitive advantage in competing with the other countries. Identifying suitable diversification areas should be considered a crucial task. To face the competition, the best way which can utilize is to identify the unique capabilities and get the maximum out of them. One of the most important factors which were able to identify was that Sri Lanka has to target global events. There are different events which are hosted in a different part of the world in different years, and Sri Lanka can target these types of events.

According to the research, most of the respondents stated that targeting high-end events created short-term and long-term economic benefits to the organization as well as the Sri Lankan events industry. Further, they mentioned that branding local events into the global generated economic sustainability and attracted a significant target market to the Sri Lankan events industry.

"Branding is the key to any business. It can change the perception of the people, drive new business, and increase awareness of the brand. As an organization, we are more focusing on branding high-end events locally and globally. It directly impacts for us to create the long term economic benefits and promote as the reputed organization in the events industry".

(Participant 01: Personal communication, 2020)

Brands make a major contribution to the adaptation and development process, which is critical for a competitive economy. It stimulates demand, reduces risk, and secures future 
earnings for the business. By generating more value for its brands, a sustainability initiative that is aligned with the positioning of a brand would generate value for businesses in the events industry. Therefore, branding events at the local and international levels stimulate the economy across the local and international regions.

Networking or the collaboration between the different industries and countries is very much important to attract high-end events in Sri Lanka. It is the exchange of knowledge and ideas, typically in an informal social environment, among individuals with a shared profession or special interest. According to the research, most of them highlighted the need for networking and created different platforms to promote local events to make them sustainable manner. The network enables them to build relationships and trust between people in their communities. Effective business networking requires daily communication follow-up to share useful knowledge that may not be easily accessible outside of the network. Further, networking between the local and international stakeholders creates opportunities to attract high-end events to Sri Lanka and build the financial strength of the country. Moreover, they can invest in innovations through that network and create more increased cash inflows to their organizations. Therefore, the network between those sectors is critically important in terms of promoting economic sustainability.

The second category of economic sustainability practice was better planning. It is essential to manage time, prevent waste and achieve efficient economics in the development process. According to the findings, most of the respondents stated that implementing cost reduction strategies made more economically sustainable organizations and achieved it through proper planning.

"Yes. We are more concerned about cost. It is the biggest challenge that we are facing in sustainable event management. But, if we can apply cost reduction strategies, I think we can make the event sustainable".

(Participant 09: Personal communication, 2020)

It is important to determine the most effective methods to reduce the cost without a negative impact on the organization. Event managers must be focused on cost reduction measures while pushing growth strategies at the same time. Sustainability can be assured by data-driven insight along with a network of procedures and controls. And also, the cost reduction program can become a source of financing for growth initiatives when performed well.

According to the findings, sustainable standardization of events created long-term economic benefits to the organization as well as the local community. It focuses on event creation and the operation process. They are developing standards to guide their employees to maintain the sustainability of the event. And also, some of the organizations have organized events based on the environmental protection guidelines.

"As a responsible organization, we always operate within the legal framework and pay all taxes related to an event. We have ISO certificate and organizing events based on the environmental protection guidelines".

(Participant 02: Personal communication, 2020)

It creates a competitive advantage and provides more value to the customers than their competitors because they are constrained by the standards. This directly impacts economic growth and attracts more visitors to the event industry. Therefore, standardization is the best practice to implement economic sustainability in the events industry. According to the research, 
the researcher has identified most of the organizations have practiced income-generating strategies throughout the events, and it increased the financial growth of them. This is an important practice for the organization, and it makes financial viability in the future. These practices should be prepared for considering the economic conditions, current status, and direction of the market. The ability to enforce these methods and policies and to remain successful over a long period prompts them to be sustainable. As a result, they can reduce their overall cost and reinvests it into new businesses.

"The company is keeping a considerable level of profit margins to cover the interest of the stakeholders and to satisfy the shareholders. Additionally, saved returns are invested in innovations to create more increased cash inflows to the company. Variations are being provided to the customers to keep the customers interested in the company and to have the business ongoing".

(Participant 12: Personal communication, 2020)

In the events industry, social sustainability is focused on how event impacts for people and societies. The stable society supports the organizations to host the events. According to the research, the researcher has been identified six key social sustainability practices, and those practices are essentially based on strengthening the local communities and cultural conservation in events. The first category of social sustainability practice was strengthening the local communities. Events are becoming the fastest growing form of tourism, and it exists for the betterment of the community. All events have a significant social impact on their participants and sometimes on their wider host communities. According to the findings, most of the respondents stated that educating the society was strengthened by the local community.

"Yes, events are generating a number of opportunities. But, the local community does not know how they can convert it to a feasible business solution. If we can educate them, they can enhance their quality of life".

(Participant 08: Personal communication, 2020)

And also, the researcher has identified most of the organizations have practiced community empowerment through the events, and it increases the social wellbeing of them. It recognizes the importance of their efforts, respects their integrity, and allows an equal distribution of the benefits of growth to be negotiated. When hosting the events, some of the organizations got support from local suppliers in the community and outsourced their services. Further, some of the event managers have used corporate social responsibility in strengthening the local community. The purpose of promoting CSR is to give something back to the host destination, building relationships with customers, and promoting personal accountability of the society. These types of programs are benefiting for the hosting organization and the local community. And also, they have used this to encourage and empowered their employees and create organizational loyalty. Therefore, this is one of the best innovative practices for organizations to establish a reputation as a socially responsible organization in the events industry.

The second category of the social sustainability practice was cultural conservation. Cultural events bring essential qualities to societies that are just as relevant as the ecological, social, and economic perspectives. Culture is essential for a sustainable society to be possible. It refers to the beliefs and practices of a society. Events can be considered as a cultural conservation strategy. 
"We try to promote our local culture and cuisine through events, especially incentives and conferences. Allowing international delegates to wear local costumes (batik and handloom dresses), taste local cuisine, visit villages to get the local experience and promote traditional Sri Lankan activities".

(Participant 11: Personal communication, 2020)

Moreover, respondents stated that compliance with the local culture and law was vital in cultural conservation. It is essential to aware of society's laws, procedures, and other administrative practices regarding the events industry. If they follow the rules of law, the host and the community can minimize the negative cultural impacts on events and gain the maximum benefits of the events.

According to the research, the researcher has been identified eight key environmental sustainability practices, and these practices, based essentially on waste management, energy efficiency, and dissemination of information in events. The first category of the environmental sustainability practice was waste management which became one of the most important practices around the Sri Lankan event companies. The aim of waste management is to understand how waste is made, by whom, where, and when, then to prevent it. They have used waste bins and recycling bins, avoid plastics and polythene, used technological equipment and online registration to reduce the wastage of the events.

"In concern with reducing carbon footprint and zero waste we provide an online platform for visitors and buyers to register and visit events that we are organizing in Maldives".

(Participant 10: Personal communication, 2020)

The second category explains how the event managers use the energy efficiently at the event. Adopting energy-efficient strategies cannot reduce the carbon footprint in full but can make the environmental friendliness to some extent. Therefore, the researcher identified as usage of LED equipment and natural air to save the energy of their events. And also, most of them stated that environmental standards and corporate socially responsible activities make more environmentally friendly events. Environmental standards are statutory legislation or civil law guidelines enforced for environmental protection and maintenance. They are set by a government and may include prohibiting specific activities, mandating monitoring frequency and methods, and requiring land or water use permits. It produces quantifiable and enforceable laws which promote the protection of the environment. Further, some of the event managers engaged in some activities like tree planting, looking after animals in their events as a CSR activity to protect the environment and to be eco-friendly. For sustainable economic growth and the wellbeing of communities, CSR is essential. Growing social consciousness is pushing corporations to reduce their burden on the environment. Socially responsible organizations are expected to bear the environmental effect of their operations, to aim to reduce waste, to emit hazardous substances, and to take action to improve the efficiency of the use of natural resources and to mitigate the negative impact on the environment. They may reduce the burden on the environment, safely store, avoid, neutralize, reduce or remove neutralize, reduce or remove pollution and environmental damage. 


\section{Discussion}

The main objective was to identify sustainable event management practices in Sri Lanka. According to the findings, the researcher has identified three major practices, namely: economic sustainability practices, social sustainability practices, and environmental sustainability practices. According to the literature, events produce impacts across the triple bottom line (TBL), which refers to the economy, socio-culture, and the environment (Dwyer, L., Mellor, R., Mistilis, N., \& Mules, 2000). And also, Tzila (2007) mentioned, sustainable events management creates a better future for the community, the economy, and the rest of the environment. Further, The British Standards Institution (2012), Byrd (2007), Maguire and Hanrahan (2013), Laing and Frost, 2010), Edwards (2005), and Getz (2009) cited, events are organized taking into consideration the economic, social and environmental impacts, and it was a balanced approach to economic activity, environmental responsibility, and social development.

Similar to the above findings, Etiosa (2012) mentioned, events can be used as a tool for destination development and branding. And also, Sustainable Event Planning Guide Denver Convention Host Committee Greening Initiative Fall (2008) revealed, sustainable events enhanced the brand and the organizational image. Further, they stated, networking among the key players as vendors, caterers, event planners, venue managers, and sponsors required to understand their intentions from the beginning of the process and help all partners to move in the right direction. Further, the study stated, event managers must use long-term perspectives in sustainable event management and planning the financial viability before undertaking any event. Failure to implement good long-term planning into the design of festivals can have negative and unsustainable effects on host communities and regions (Smith, 2009). Long-term planning helps organizers to make more sustainable decisions in events (Dickson \& Arcodia, 2010). Moreover, Stettler (2011) cited that sustainable education is a powerful driver to inspire and motivate people to engage in sustainable event management practices. Dickson and Arcodia (2010) mentioned, educate the society on sustainability practices improves knowledge and makes awareness to strengthen the local community and the social wellbeing.

The results indicated Sri Lankan event management organizations used CSR to encourage and empowered their employees and create organizational loyalty. These activities are benefiting for the hosting organization and the local community. Similarly, Pfeffer (2011) and Caulfield et al. (2001) cited, CSR activities influenced social development and employee wellbeing. Further, the study revealed, cultural conservation impacts the society to work together to preserve the cultural events and to see that this practice is passed on from one generation to the next. Maguire and Hanrahan (2013) mentioned events create a cultural identity within the destination, and it was an element of community enrichment. Yeoman et al. (2004) stated cultural heritage preservation is as critical as the protection of other resources. Moreover, sustainability managed events promote greater involvement of both hosts and visitors in local culture and heritage (Edwards, 2005).

Moreover, Laing and Frost (2010) stated, there are a number of green practices in events, including methods for waste reduction, programs for recycling, and water conservation. Braungart et al. (2007) cited green practices include waste minimization and recycling, energy management, pollution reduction, zero emissions, water savings, material use reduction, material life cycle assessment, and toxicity reduction. Additionally, Dickson and Arcodia (2010) mentioned, 
engaging in environmental CSR activities increases credibility, addresses consumer needs and desires, mitigates negative media coverage, and creates a stronger relationship network. Fombrun et al. (2000) stated this helps to build the reputation, attract resources, enhance its performance and build competitive advantage.

\section{CONCLUSION}

The event industry is rapidly developing and makes a significant contribution to business and leisure-related tourism. It is high time that Sri Lanka showcases sustainable practices in events as well as in other industries. According to the results found by the researcher from the content analysis, all the stakeholders should understand the significance of using sustainable practices within the events industry.

The results indicated there were three sustainability practices as economic sustainability practices, social sustainability practices, and environmental sustainability practices. Economically sustainable practices were targeting high-end events and better planning. Branding, networking, cost reduction strategies, standardization, and income-generating strategies were implemented by the event management organizations to gain the economic benefits from the events. Socially sustainable practices were strengthening the local communities and cultural conservation. Educate society, community empowerment, corporate social responsibility, promote traditional events, comply with local culture, and comply with law were implemented by the event management organizations to gain the benefits from the events to the organization, customers, and society. Environmental sustainable practices were waste management, energy efficiency, and dissemination of information. Usage of waste bins, avoid plastics and polythene, usage of technological equipment, online registration, usage of natural air, usage of LED equipment, environmental standards, and CSR activities were implemented by the event management organizations to make the green events.

The findings elucidate effective theoretical and managerial implications for event organizers, government, and residential communities where events are held. Maximizing the awareness of attendees with sustainable education, developing a sustainable event model, adapt to green-related technology, introduce green venues and promote sustainable events, government involvement of making policy framework and public-private partnership create long term and sustainable legacies for host communities and development of sustainable event management in Sri Lanka.

\section{LIMITATION \& FURTHER RESEARCH}

Alongside credibility, several limitations on the present research are asserted. Due to the lack of prior research studies about sustainable event management, the study only has limited literature. Further, in Sri Lanka, there is only one legal body that represents the events organizations. Moreover, the researcher faced difficulties in contacting resource persons for the interviews and data collections as the existing pandemic situation in the country.

Additionally, future researchers can be conducted the same research in a wider manner based on all event stakeholders as attendees, responsible government organizations, and local community. Since the study was conducted in the qualitative method, it cannot provide significant 
proof regarding the conceptual indicator model. In order to validate this concept indicator model, future researches can be conducted in a quantitative analysis method.

\section{REFERENCES}

Ahmad, N. L., Rashid, W. E. W., Razak, N. A., Yusof, A. N. M., \& Shah, N. S. M. (2013). Green Event Management and Initiatives for Sustainable Business Growt. International Journal of Trade, Economics and Finance, 4(5), 331-335. https://doi.org/10.7763/ijtef.2013.v4.311

Arcodia, C., \& Reid, S. (2003). Professionalising Event Practitioners: The educational role of event management associations. Advances in Convention, Exhibition \& Event Research, Convention and Expo Summit., September 2014, 31. http://espace.library.uq.edu.au/view/UQ:10177/ca_sr_profep.pdf

Braungart, M., McDonough, W., \& Bollinger, A. (2007). Cradle-to-cradle design: creating healthy emissions - a strategy for eco-effective product and system design. Journal of Cleaner Production, 15(13-14), 1337-1348. https://doi.org/10.1016/j.jclepro.2006.08.003

Byrd, E. (2007). Stakeholders in sustainable tourism development and their roles: applying stakeholder theory to sustainable tourism development. Tourism Review, 62-2, 6-13.

Caulfield, J., Polèse, M., Stren, R., \& Polese, M. (2001). The Social Sustainability of Cities: Diversity and the Management of Change. In Canadian Public Policy / Analyse de Politiques (Vol. 27, Issue 3). https://doi.org/10.2307/3552480

Chiu, L. K., Ramely, A., \& Abdul Wafi, A. (2020). Make Green Growth a Priority: Issues and Challenges in Organising Green Sports Tourism Events. Malaysian Journal of Sustainable Environment, 7(1), 53. https://doi.org/10.24191/myse.v7i1.8910

Dickson, C., \& Arcodia, C. (2010). Promoting sustainable event practice: The role of professional associations. International Journal of Hospitality Management, 29(2), 236-244. https://doi.org/10.1016/j.ijhm.2009.10.013

Dwyer, L., Mellor, R., Mistilis, N., \& Mules, T. (2000). A FRAMEWORK FOR ASSESSING 'TANGIBLE' AND 'INTANGIBLE' IMPACTS OF EVENTS AND CONVENTIONS (pp. 175-191). Event Management.

Dwyer, L., Forsyth, P., \& Spurr, R. (2005). Estimating the impacts of special events on an economy. Journal of Travel Research, 43(4), 351-359. https://doi.org/10.1177/0047287505274648

Edwards, D. (2005). INCORPORATING SUSTAINABILITY IN MEETINGS AND EVENT MANAGEMENT EDUCATION. 1(1), 30-45.

Endorser. (2019). Principles for Sustainable Events. https://www.eventscouncil.org/Portals/0/EIC Documents/Sustainability/Principles for sustainable events.pdf?ver=2019-01-18-123244-787

Etiosa, O. (2012). THE IMPACTS OF EVENT TOURISM ON HOST Case : the City of Pietarsaari Thesis Degree Programme in Tourism. April, 1-63.

Fombrun, C. J., Gardberg, N. A., \& Sever, J. M. (2000). The Reputation QuotientSM: A multistakeholder measure of corporate reputation. Journal of Brand Management, 7(4), 241-255. https://doi.org/10.1057/bm.2000.10

Getz, D. (2009). Policy for sustainable and responsible festivals and events: institutionalization of a new paradigm. Journal of Policy Research in Tourism, Leisure and Events, 
1(1), 61-78. https://doi.org/10.1080/19407960802703524

Hall, J. K., Daneke, G. A., \& Lenox, M. J. (2010). Sustainable development and entrepreneurship: Past contributions and future directions. Journal of Business Venturing, 25(5), 439-448. https://doi.org/10.1016/j.jbusvent.2010.01.002

Higham, J. (2005). Sport Tourism Destination; Issues and Opportunities and Analysis. Taylor and

Francis.

https://books.google.lk/books?id=z3cABAAAQBAJ\&pg=PA96\&lpg=PA96\&dq=sustainable+develo pment+by+(shapcott,+1998).\&source=bl\&ots=sh4x7M2U2f\&sig=ACfU3U17Kv7x86pTU211Wtnp xFW6hQa0aA\&hl=en\&sa=X\&ved=2ahUKEwj_9v-

ugNruAhUQ63MBHW5eBJEQ6AEwA3oECAUQAg\#v=onepage\&q=susta

Holmes, K., Hughes, M., Mair, J., \& Carlsen, J. (2015). Events and sustainability. In Events and Sustainability. https://doi.org/10.4324/9781315813011

Jones, X., \& Scanlon, M. (2010). Signing to a Greener Tune; Current status of the music industry in addressing eJones, M Scanlon, X. (2010). Signing to a Greener Tune; Current status of the music industry in addressing environmental sustainability. https://docplayer.net/8420054-Singing$t . \quad$ https://docplayer.net/8420054-Singing-to-a-greener-tune-current-status-of-the-musicindustry-in-addressing-environmental-sustainability.html

Laing, J., \& Frost, W. (2010). How green was my festival: Exploring challenges and opportunities associated with staging green events. International Journal of Hospitality Management, 29(2), 261-267. https://doi.org/10.1016/j.ijhm.2009.10.009

Maguire, K., \& Hanrahan, J. (2013). Sustainable event management in Ireland: A local authority perspective. ... Hospitality Research in Ireland ... http://cual.openrepository.com/cual/handle/10759/346270

O’Sullivan, D., \& Jackson, M. (2002). Festival Tourism: A Contributor to Sustainable Local Economic Development? Journal of Sustainable Tourism, 10, 325-342. https://doi.org/10.1080/09669580208667171

Pfeffer, J. (2011). Building Sustainable Organizations: The Human Factor. SSRN Electronic Journal, February. https://doi.org/10.2139/ssrn.1545977

Schulenkorf, N., Giannoulakis, C., \& Blom, L. (2018). Sustaining commercial viability and community benefits: management and leverage of a sport-for-development event. European Sport Management, 1-18. https://doi.org/10.1080/16184742.2018.1546755

Smith, A. (2009). Theorising the Relationship between Major Sport Events and Social Sustainability. Journal of Sports \&Tourism, Volume 14(2-3), 109-120. https://doi.org/10.1080/14775080902965033

Stettler, S. L. (2011). Sustainable event management of music festivals: An event organizer perspective. Vasa, http://pdxscholar.library.pdx.edu/cgi/viewcontent.cgi?article=1256\&context=open_access_etds

Sustainable Event Alliance. (2011). Sustainable Event Alliance. http://www.sustainableevent-alliance.com/page_id $=27 \% 0 \mathrm{D}$

Sustainable Event Planning Guide Denver Convention Host Committee Greening Initiative Fall. (2008). Sustainable Event Planning Guide Greening Initiative.

The British Standards Institution BSI Standards Report to the Department of Business, Innovation and Skills Use of BIS funding for the financial year 1 April 2011 to 31 March 2012. 
(2012). April 2011.

Tzila, C. (2007). Event greening : is this concept providing a serious platform for sustainability best practice? This thesis uses a proposed rating system to measure the sustainability factor of event greening projects and in so doing remove the 'green wash ' syndrome a. March.

United Nations Environment Program. (2009). Green Meeting Guide: Roll Out The Green Carpet For Your Participants. https://wedocs.unep.org/handle/20.500.11822/7834

Wickramasinghe, K. (2018, August 20). Millions of tourists,millions of opportunities. The Island News Paper. http://www.ips.lk/talkingeconomics/

Yeoman et al. (2004). Festival and Events Management: An International Arts and Culture Perspective (1st Editio). Butterworth Heinemann. 